\title{
Different forms of swimmers' final weeks of pre-competition preparation
}

\author{
Authors' Contribution: \\ A Study Design \\ B Data Collection \\ C Statistical Analysis \\ D Data Interpretation \\ E Manuscript Preparation \\ F Literature Search \\ G Funds Collection
}

\author{
Kamil Sokołowski ${ }^{1 \text { ABDEF, Marek Strzała }}{ }^{1 \text { ADE }}$, Arkadiusz Stanula ${ }^{2}$ DE \\ ${ }^{1}$ Department of Water Sports, University of Physical Education in Krakow, Poland \\ 2 Department of Sports Training, \\ The Jerzy Kukuczka Academy of Physical Education in Katowice, Poland
}

Key words: peak form preparation, taper phase, immediate preparation for competition, swimming performance, overreaching.

\section{article details}

Article statistics: Word count: 6,167; Tables: 1; Figures: 2; References: 76

Received: May 2020; Accepted: July 2020; Published: December 2020

Full-text PDF: http://www.balticsportscience.com

Copyright ๑ Gdansk University of Physical Education and Sport, Poland

Indexation: Celdes, Clarivate Analytics Emerging Sources Citation Index (ESCI), CNKI Scholar (China National Knowledge Infrastructure), CNPIEC, De Gruyter - IBR (International Bibliography of Reviews of Scholarly Literature in the Humanities and Social Sciences), De Gruyter - IBZ (International Bibliography of Periodical Literature in the Humanities and Social Sciences), DOAJ, EBSCO - Central \& Eastern European Academic Source, EBSCO - SPORTDiscus, EBSCO Discovery Service, Google Scholar, Index Copernicus, J-Gate, Naviga (Softweco, Primo Central (ExLibris), ProQuest - Family Health, ProQuest - Health \& Medical Complete, ProQuest - Illustrata: Health Sciences, ProQuest - Nursing \& Allied Health Source, Summon (Serials Solutions/ProQuest, TDOne (TDNet), Ulrich's Periodicals Directory/ulrichsweb, WorldCat (OCLC)

Funding: This research received no specific grant from any funding agency in the public, commercial, or not-for-profit sectors.

Conflict of interests: Corresponding author:

Open Access License:
Authors have declared that no competing interest exists.

Kamil Sokolowski, Academy of Physical Education, Cracow, Poland; Department of Water Sports, al. Jana Pawła II 78, 31-571 Kraków, Poland; e-mail: sokolowski.kc@gmail.com ORCiD 0000-0002-0993-0170

This is an open access article distributed under the terms of the Creative Commons Attribution-Non-Commercial-NoDerivatives 4.0 International (https://creativecommons.org/licenses/by-nc-nd/4.0/), which permits use, distribution and reproduction in any medium, provided the original work is properly cited, the use is non-commercial and is otherwise in compliance with the license. 


\section{INTRODUCTION}

Training aims at increasing different athletes' skills, which contribute to the final performance $[1,2]$. In the whole training process, the taper phase seems to be crucial in terms of peak form preparation [3]. This relatively short and rarely repeated training period is to bring out swimmers' skills and abilities which have been formed for many weeks during the overload training period. The peak form preparation process usually takes place twice a year.

During the immediate preparation for competition (IPC) as well as in the TP training, a well-known physiological mechanism of supercompensation is utilized [3]. The athlete's body response to training stimuli is delayed. Olbrecht [4] presented some prescriptive recommendations for the optimum rest duration after a specific type of training work. For example, intensive anaerobic work will require 40 to 60 hours' regeneration period, and after intensive aerobic work it should be 24 to 30 hours. Good understanding of the supercompensation process is crucial not only when it comes to peak form preparation, but also for the correct daily swim training execution $[3,5]$.

It could be difficult for an inexperienced swimming coach to choose the correct form of peak form preparation [3]. This is due to the fact that various training procedures are often named with seemingly synonymous terms. Only few studies have shown the dissimilarities between different forms of peak form preparation. There are some scientific discussions (Bosquet et al. [6], Maglischo [7], Mujika et al. [8], Mujika and Padilla [9], Olbrecht [4], Papoti et al. [3], Platonov [10, 11], Trappe et al. [12]) on the training procedure during the final weeks leading to the competition. However, those studies merely focus on the differences between immediate preparation for competition (IPC) and the taper phase (TP) that affect current and future swimmers' physical abilities.

The purpose of this literature review is to present and compare different forms of peak form preparation in swimming with a general explanation of physiological mechanisms involved in the method used here. Possible performance changes due to prevalent training procedures and risk of potential failure will also be taken into consideration in order to identify the most effective one. The comparison between IPC and TP includes time structure as well as the quantity and the type of training work. Possibilities of adapting IPC and TP to individual swimmers' abilities and distance specialization, as well as to various levels of recovery capability, have been also discussed.

We assume that: 1) IPC and TP strategies exploit different physiological mechanisms in order to reach a higher performance level, 2) as a relatively new method, TP will be a more effective way of peak form preparation than IPC, mainly because of greater individualization possibilities.

\section{MATERIAL AND METHODS}

Literature search (from 1969 to 2018) was conducted using Google Scholar. The search words were: peak form, tapering, taper phase, swimming, main competition, performance, supercompensation. Resources of the University of Physical Education in Cracow library were also searched, with the main purpose to include rare books and articles in the conducted literature review. Books significantly related to the topic were included into review. In November 2019 a repeated search was conducted in order to include possibly missed articles which were published in 2019. It resulted in adding 3 new publications into the review. The inclusion criteria for the publication were: (i) appeared in a peerreviewed academic source, (ii) was directly related to the human competitive swimming, exercise physiology, methodology of sports training. Exclusion criteria: (i) publication not directly related to the topics mentioned in the review questions. 


\section{RESULTS}

The initial search yielded 244 results. The title and abstract of each article were evaluated for relevance to the issues that were to be discussed. Preliminary selected papers and books were searched for the other appropriate bibliography items which could be included in the review. The final number of research papers and books directly related to the discussed issue and explaining the concepts of IPC and TP was 38. Other publications became mainly a basis for explaining physiological mechanisms of both training concepts.

\section{Immediate Preparation for Competition}

IPC is a training phase that is marked by the highest training volume and intensity levels, which interchange in a sudden way. According to Issurin [13], the main purpose of IPC (or Final Stage Preparation) is to reach the highest possible fitness level. Lewin [14] claims that in swimming IPC (Ger. Unmittelbar Wettkampfvorbereitung) consists in repetition of miniaturized annual cycles in terms of its structure and content. Perkowski [15] defines IPC as "shortened, modified copy of preparatory and competition phases, with consideration for climate conditions and specification of competition, whose goal is to reach a peak form". This process involves preliminary degradation of physiological abilities (overreaching) because of accumulated fatigue [16]. On the other hand, fatigue (overreaching) should also initiate the process of physiological supercompensation in the recovery period and should lead to substantial performance improvement $[2,5,17,18$, $19,20,21]$. Olbrecht [4] suggested that fatigue could cause some desirable disorders of: intercellular $\mathrm{pH}$ value, neuromuscular stimulation processes, concentration and activity of enzymes and hormones and glycogen concentration [6, 22, 23]. As a result, after a recovery period, when the training load is very low, swimmers' bodies will not only regain previous levels of homeostasis, but due to supercompensation, they may reach a higher level of, for example, anaerobic capacity or ability to utilize lactate acid [2, 24, 25, 26]. Urhausen and Kindermann [26] claim that overreaching should be avoided due to its unpredictable effects. Busso [27] pointed out that too much training with insufficient | recovery between sessions could provide a level of performance lower than expected.

All the prevalent IPC forms, 6-week IPC, 8-week IPC (described by Platonov [10, 11], and 9-week IPC described by Siewierski [28]) consist of the same phases: accumulation (two to six weeks), transmutation (two to four weeks), realization (eight to fifteen days). It is important to point out that they are nearly identical to mesocycle blocks in Issurin's [29] Block Periodization Concept. Similarities also include the order and duration of both of them.

The crucial issue of the IPC that has been discussed in an early publication by Matveyev [30] is a necessity to imitate competition conditions, which allows for easier acclimatization to a particular climate and time characteristic of the main start [31]. Platonov [32] mentions that "numerous competitors begin IPC six to eight weeks before the competition and it includes two specific mesocycles." The first mesocycle is characterized by a very high training volume which is later replaced by very high training intensity, often enhanced by e.g. hypoxic training in the mountains. The second mesocycle has a low training volume and average training intensity together with a lot of recovery techniques (mental and biological restoration), and its purpose is to provide proper conditions for recovery in order to reach a higher performance level.

\section{6-Week IPC recommendations (Platonov [10])}

6-week IPC was used for the first time by the East Germany swimming national team during preparation for the Montreal Olympic Games in 1976. The Games turned out to be very successful for them and because of that the 6-week IPC became very popular. 
6-week IPC begins with five to six days of active recovery. Then swimmers start a 3-week base training mesocycle, which is divided into two 10-day stages. The training process during this mesocycle usually takes place in mountains (around 2500 meters above the sea level). The first part of the mesocycle is very similar to the base training period from the beginning of the season. It is necessary to do a lot of aerobic and mixed training work together with strength training. Strength training is called "special", because it utilizes swimming trainers, which allow imitating in-water training, by retaining a proper movement technique. After the first 10-day stage, it is desirable for a swimmer to take part in control-competition that helps to evaluate the current level of swimmer's adaptation to high training loads. Since the main goal of this part it is to execute high-volume training with a high amount of strength work, it is believed that an extremely high volume of training is necessary to induce a proper swimmer's body response, particularly when it comes to training senior swimmers. One can achieve this by implementing a high volume of training in low oxygen partial pressure conditions as well. It is expected that after this type of training a swimmer will return to the initial level of aerobic-anaerobic and strength abilities, which have decreased due to specialized training before IPC. It is worth mentioning that Costill et al. [33] demonstrated that after 10 days of very intense training, swimmers reduced muscle glycogen levels and experienced difficulties with glycogen resynthesis. On the other hand, Kirwan et al. [34] reported that swimmers could double their training volume for up to 10 days without either improving performance or developing stress due to overtraining.

The second 10-day stage of the base training mesocycle is completely different from the first one in terms of the training content. The training volume is significantly reduced whereas training intensity increases. Training work is designed to enhance speed abilities and race-specific endurance, which could both be trained by swimming sets with intensity equal or higher than those to be achieved during the incoming competition. Furthermore, it is common to practice turns and block starts and transition to diving, swimming with the race speed between flags and the wall, maintaining high precision as far as swimming technique is concerned. After completing a 3-week base training mesocycle, the 2-week pre-competition mesocycle begins carried out at a lowland level. In order to enable the recovery and supercompensation process, after the highly fatiguing base mesocycle, the training volume is much decreased. During this mesocycle training is specialized, and the sole purpose of this training phase is to refine the technique, race tactics and the psychological attitude. Platonov [10] claims that training in this period is highly individualized but he did not elaborate on what he meant by that. Mental and biological regeneration is a commonly used means for a proper recovery at this stage.

\section{8-Week IPC Recommendations (Platonov [10, 11])}

This form of IPC came into being in the early 1980s and it is constructed as follows. After five to six days of active recovery, there begins a 2-week base training mesocycle (in lowlands). In this period training is to develop aerobic capacity. In the dryland training an emphasis is put on developing strength and the range of motion of the joints which are involved in propulsive movements (general flexibility). Although it is necessary to implement a high training volume, it is increased gradually, because a swimmer has to adapt to high training loads which are planned for the next mesocycle. The next 3-week base training mesocycle takes place in mountains, about 2500 meters above the sea level. It is preceded by one day of rest and then there is a time for adaptation, the length of which depends on how hypoxemia affects individual swimmers, but it lasts no longer than six days. When a swimmer is adapted to hypoxic conditions, a training load increases, often to maximum values. The training process is extremely intense. It includes competitions on the eleventh and seventeenth days of this mesocycle with one day of rest after each of them. The last pre-competition mesocycle, which takes place at a lowland level, lasts 
three weeks and is divided into 3 microcycles. In the first microcycle, training volume and intensity distinctly decrease, which is connected with a simultaneous process of reacclimatization to lowland conditions. The second and third microcycles are intended to provide active recovery with the implementation of wellness. It is also a time to train speed by practicing diving block starts and diving, turns, relay starts and short sprints. Four to five days before competition, there are 1-2 training units with the maximum training load in order to stimulate the swimmer's body with the effort level similar to the race.

\section{TAPER RECOMMENDATIONS}

Tapering or the taper phase (TP) is a process of reducing the amount of training before the main competition, the span of which may differ [18]. Similarly to the IPC, the aim of the taper phase is to prepare a peak form for the days of competition [35]. Tapering is commonly utilized in various forms which are often quite similar $[1,6,7,8,20,36]$. Training processes in IPC and TP (and overload training period which precedes TP) are not completely different but cannot be considered as the same procedure. Mujika and Padilla [37] defined TP as: "a progressive nonlinear reduction of the training load during a variable period of time, in an attempt to reduce the physiological and psychological stress of daily training and optimise sports performance." Similarly, Bompa and Haff [1] claim that reducing the fatigue level is the main factor which determines further higher performance abilities. The fatigue level could be decreased by adjusting three of the training factors: intensity, volume and frequency [38]. Bosquet et al. [6], Maglischo [7], and Mujika and Padilla [37] presented some recommendations for proper training during TP:

a. Intensity of training should not be decreased significantly; the best solution is to maintain the level preceding TP [6, 35, 37, 39].

b. Volume of training should be much decreased, even by $75 \%$; it is mostly reduced to $40-60 \%$ of the training volume in the pre-taper period [6, 35, 37].

c. It is recommended to reduce the amount of training units up to $20 \%$, but not more; larger reductions could cause a loss of technical abilities [6, 35, 37].

Maglischo [7] recommends 2-3 weeks TP. Maglischo presented TP as a period of gradual training volume reduction with simultaneous changes in utilizing various training intensity zones. In TP, the amount of endurance (aerobic) intensities (EN1, EN2, EN3) gradually decreases together with an increase in REC training. Maglischo [7] identified three types of TP on the basis of the duration and the current period of the training plan. The first one is the major taper, which lasts $2-4$ weeks and is implemented only before main competitions. The major taper takes place maximum twice a season as an element of complex preparation to the main competition. The second taper form, minor taper, is implemented when there is a need to reach the peak form for a short period of time during the preparatory training phase. Some specialists criticize using this TP form when there are only a few weeks left to major taper. Many consider this as reason for failure during the main competition, because there is a lack of training volume then during the base training period before the major taper. The advantage of using minor taper is temporary improvement in swimmer's motivation and a chance for him/her to recover. The last form of TP is retaper. It is used when two important competitions take place within 3-5 weeks. In this case, it is necessary to maintain the same performance level all the time. Such situations occur, for instance, when qualifying competition precedes the main competition. It is also important that the peak form stays only 7-10 days after major taper, and that is why retaper is so crucial. Anyway, it should be stressed that it is a solid preparatory phase with a high volume of training, and proper intensity should be our key concern [7]. Bosquet et al. [6] indicate that in terms of further performance improvement, a 2-week taper phase is the most beneficial. 
Olbrecht [4] pointed out differences in the duration of TP which depend on swimmer's distance specialization. He also suggested the most beneficial proportions between the duration of the base training period and TP. Distance swimmers, after quite a long base training period (from four to fourteen weeks), should go through short TP (from four to fourteen days), while sprinters will benefit the most from a short base training period (from one to five weeks) and comparatively long TP (from two to four weeks). Maglischo [7] divided swimmers into two groups: sprint swimmers (from nineteen seconds to two minutes of effort), distance swimmers (from four to twenty minutes of effort). For each of these groups, he identified training parameters for TP. For more details, authors recommend Swimming Fastest [7] by Ernest Maglischo.

Distance swimmers should maintain high training volume, and the duration of taper has to be shorter than in the case of sprinters. It is because a distance swimmer has to preserve a high aerobic capacity level, which could decrease after only a few days of rest (or through elimination of training intensities: EN1, EN2, EN3) [4, 40]. It is not necessary for a distance swimmer to have a long rest period to recover. During this time, reduced training can elevate carbohydrate utilization [39] and maximize muscle glycogen storage $[41,42]$. On the other hand, sprinters need to go through longer TP with higher reduction of training volume, which helps them to increase an ability to generate power from anaerobic energy sources. Trinity et al. [43] claim that neurological adaptations which contribute to an increase in mechanical power may require a longer period (14-21 days). Sprinters' fatigue level tends to be higher and recovery duration longer as a result of greater anaerobic work [4, 7]. Contrary to previous authors, Trinity et al. [43] claim that a different response to taper (early, late adaptation) did not appear to be dependent on distance specialization. It is more due to a multitude of factors (inter alia): genetics, nutrition, the initial level of training, experience.

Bosquet et al. [6] used a meta-analysis to assess the effects of various alternations of taper components on performance emphasizing the importance of the volume of training work and the duration of taper. They indicate that these two parameters are correlated with further performance level. They also pointed out the training load should not be reduced by way of decreasing training intensity and frequency, because it does not result in significant improvement in performance or even causes its decrease [33]. It also worth mentioning that maintaining a training intensity level was determined by Mujika et al. [37] as one of the crucial parameters affecting the level.

According to the results presented by Bosquet et al. [6], optimum gains are obtained with a taper which lasts from eight to fourteen days. In this case there is a balance between positive effects of the training load reduction and the negative ones related with a long period of substantial training work reduction. Bosquet et al. [6] claim that it is ineffective to go through tapering intervention longer than four weeks, because it may lead to performance decrease. Analysis made by these authors showed that the biggest performance improvement is provided by a taper phase lasting 2 weeks.

Mujika and Padilla [37] identified a few types of tapering. They differ in terms of the methods of training load reduction. They presented a classification of tapering methods containing two main groups (divided into sub-groups): 1) progressive taper patterns 2) non-progressive taper patterns. Progressive taper patterns are marked by a gradual, progressive manner of reduction. In non-progressive taper, which could be named steptaper as well, the training load decreases suddenly to the pre-set level (Figure 1).

In progressive taper, training load reduction can be made either in a linear or exponential way. In this group, Mujika and Padilla [9] defined: linear taper, exponential taper - slow 
decay, exponential taper - fast decay (Fig. 1). Mujika and Padilla [9, 44] and Banister et al. [45] also concluded that exponential taper (and especially exponential taper - fast decay) was a better strategy providing performance improvement than a step-taper and exponential-taper - slow decay protocols. Exponential taper - slow decay has been reported to result in the largest improvements in endurance performance [45].

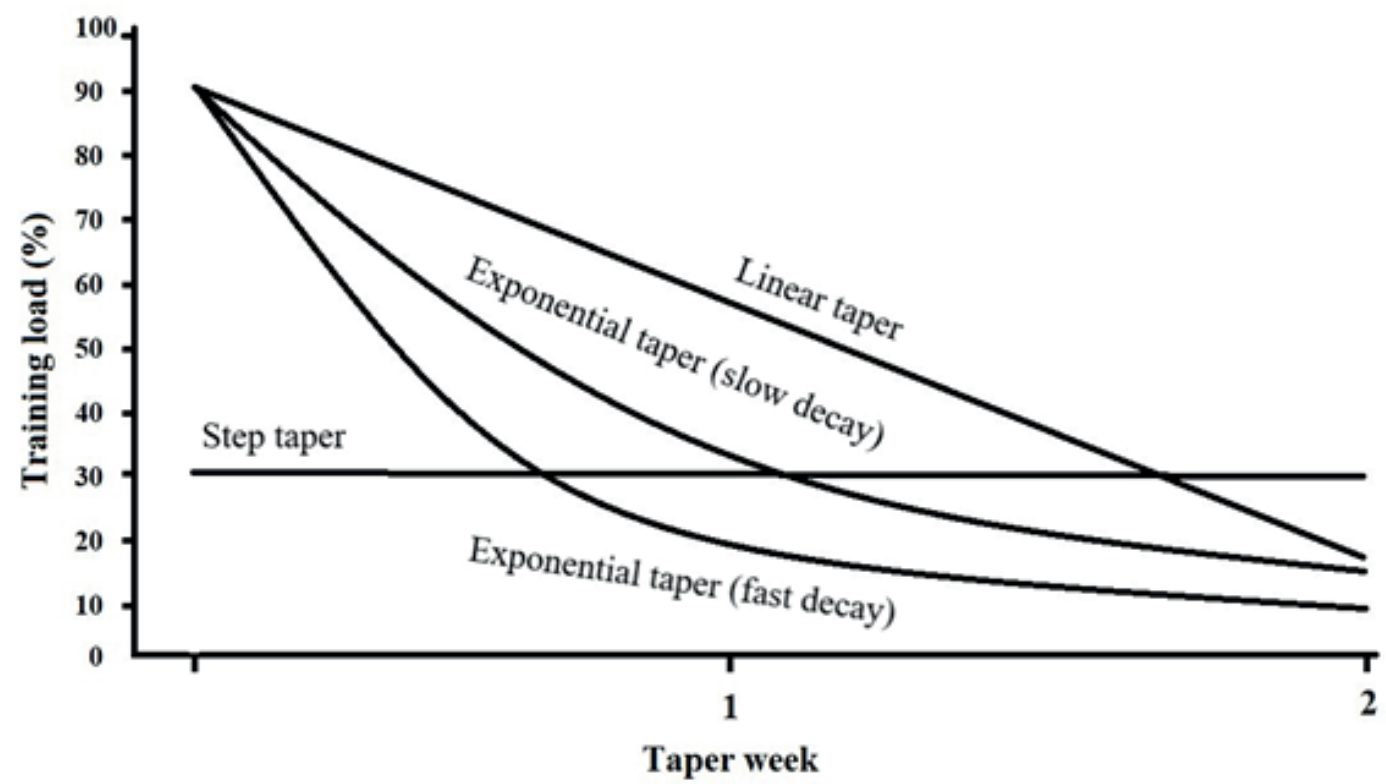

Fig. 1. Visual representation of the different taper patterns (adapted from: [9])

When comparing structures of IPC and TP, it is worth mentioning that in most cases in the TP strategy (contrary to 6-week IPC and 8-week IPC) altitude training is not commonly used. Different training procedures and inconclusive effects of peak form preparation training in altitude conditions might be the main reasons why this is still considered a non-standard, experimental method [46].

Klusewicz and Malczewska [47] also discussed the issue of evaluation difficulties when it comes to swimmers' altitude training: "evaluation of the effects of the altitude training is difficult due to individualized physiological reactions of athletes." It is not the only factor hindering evaluation of training work done under low oxygen partial pressure $\left(P_{1} O_{2}\right)$ conditions and further training effects. Wolski et al. [48] mentioned a few factors which affect great variability of the altitude training effects. They are: height above sea level (ipso facto the hypoxia value), time spent in mountains, current stage of training, type of training work, athlete performance level, possibility of acute mountain sickness (AMS).

Klusewicz and Malczewska [47] questioned the commonly recognized causes of large adaptation changes observed in Hct and Hb. Referring to Berglund [49] and Boutellier et al. [50], they claim that haematocrit changes might be caused by low blood plasma volume due to dehydration.

Hellard et al. [51] presented a new approach in their research on TP. They specified a training structure which is a fusion of TP and IPC. They indicated four types of training reduction during TP and four forms involved in the period of high training loads preceding TP - overload training period (OP). The duration of both TP and OP was 3 weeks, which gives in total 6 weeks of the peak form preparatory training period (F6T - final six weeks 
of training) (Fig. 2) Discussion of the effects of several F6T forms showed that the most effective one it is F6T in which:

1) in OP the highest training volume is placed in the $1^{\text {st }}$ week. Then it decreases in a slow-decay exponential way;

2) in TP training volume decreases in a slow, close-to-a-linear way.

Many researchers have emphasized the feasible positive effects of the overload training period preceding the taper $[6,17,22,23,52,53,54]$. Although greater training volume and/ or intensity before the taper was shown to result in higher performance gains, it required a greater reduction in the training load, carried out in a longer period [22, 23, 27, 54].

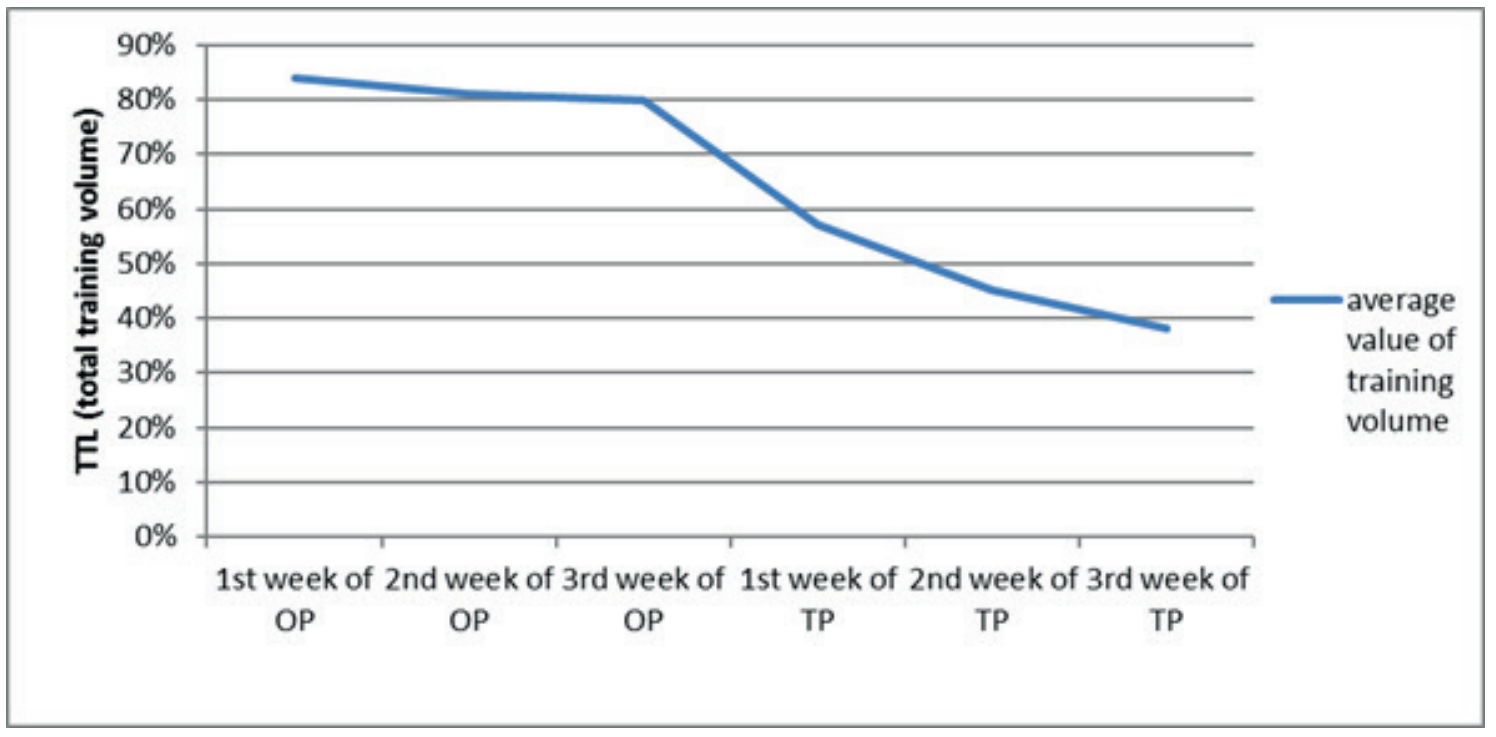

Fig. 2. The most beneficial theoretically form of training volume reduction during a 6 -week period preceding the main competition (adapted from [51])

\section{Comparison between the IPC and TP strategies}

6-week IPC and 8-week IPC structures are very similar and include phases of: accumulation, intensification and transformation (supercompensation). There are differences in the duration of each phase and in the quantity or type of the training load. In both forms, during the first phase of accumulation, water training is mostly aerobic and versatile. It is to develop aerobic capacity through aerobic and mixed aerobic-anaerobic training [60]. It is combined with specialized strength dryland training (mostly using specific swimming equipment, such as a swimming ergometer, a resistance stretch cord, etc.). In the intensification phase, the volume of training decreases with a simultaneous increase in intensity (even to maximum values). In 6-week IPC swimmers continue their training in hypoxia, while in 8-week IPC they start training in mountains only then, with a few days of adaptation to low oxygen partial pressure conditions. In the transformation phase, the training load is substantially reduced in a rapid, step way. It is combined with body biological restoration and rest in lowland conditions. The purpose of this procedure is to reach the peak form due to the supercompensation effect. Training work is highly specified in order to shape race-specific abilities. 


\begin{tabular}{|c|c|c|}
\hline & IPC & Taper \\
\hline Mechanism of peak form preparation & $\begin{array}{l}\text { Supercompensation (after preceding } \\
\text { period of overload training [2]; } \\
\text { overreaching). }\end{array}$ & $\begin{array}{l}\text { Supercompensation (almost total } \\
\text { fatigue elimination) [43]. }\end{array}$ \\
\hline Duration & $\begin{array}{l}\text { Strictly established in each form of } \\
\text { IPC (6-week, 8-week, 9-week) [10, } \\
\text { 11, 28]. }\end{array}$ & From four days to five weeks $[4,6,7]$. \\
\hline Phase structure & $\begin{array}{l}\text { Phases of accumulation, } \\
\text { intensification and transformation } \\
\text { [28]. }\end{array}$ & Not applicable \\
\hline Training volume & $\begin{array}{l}\text { Very high in accumulation phase, } \\
\text { decreases in further phases }[10,28] .\end{array}$ & $\begin{array}{l}\text { Reduction through entire taper } \\
\text { period in a linear, exponential slow- } \\
\text { decay, exponential fast-decay or } \\
\text { step way [9]. }\end{array}$ \\
\hline Training intensity & $\begin{array}{l}\text { Reaches very high level in } \\
\text { intensification phase, sudden } \\
\text { decrease in transformation phase } \\
{[10,28] \text {. }}\end{array}$ & $\begin{array}{l}\text { At the same level through the entire } \\
\text { taper period }[6,7,9,20,37,44,55 \text {, } \\
56,57] \text { or increased [58] }\end{array}$ \\
\hline $\begin{array}{l}\text { Possibility of training } \\
\text { individualization for distance } \\
\text { groups and swimmer's regeneration } \\
\text { abilities. }\end{array}$ & $\begin{array}{l}\text { Low - only when it comes to training } \\
\text { sets. Duration of each phase cannot } \\
\text { be changed. }\end{array}$ & $\begin{array}{l}\text { High - training content (training } \\
\text { sets), duration of the period, } \\
\text { selection of the form of the training } \\
\text { load reduction }[6,20,38,59] \text {. }\end{array}$ \\
\hline
\end{tabular}

Preparation for the main competition through TP is a training strategy different from IPC, because it is based on a more efficient mechanism of gentle training load reduction in a specific period preceding the main competition [1]. In IPC, swimmers are highly and abruptly strained with a very high training load. This process results in a rapid decrease of performance ability due to fatigue accumulation, but it is done on purpose to stimulate further substantial supercompensation. However, a rapid (step) increase in the training load involves a high risk of overtraining (and inevitably demands a long recovery period) or even of complete failure of the peak form preparation [28, 61]. Halson and Jeukendrup [62] pointed out that when the balance between the training stress and recovery is disproportionate, overreaching and possibly overtraining may develop. Flynn et al. [61] reported that, during swimmers' intense training period, there were alternations in free testosterone, total testosterone and $\mathrm{CK}$, which are hormonal markers of training stress.

In both IPC and TP, the expected level of fatigue is a crucial factor, but in TP it fluctuates less. According to Zatsiorsky [63], a higher fatigue level during the main competition is the main reason for lower performance. Yamamoto et al. [64] claim that the level of expected fatigue indicators could be established through analysis of biochemical changes in organism and of blood indices. The crucial blood constituents are serum creatine phosphokinase (CPK) and blood haemoglobin concentration $(\mathrm{Hb})$. It was revealed that positive changes in those indices are due to taper and contribute to better performance as well as to better psychological state. Swimmers tend to feel: "light", less fatigued. They also sleep better, which enhances the supercompensation process [37]. This effect is obtained by a gradual reduction of the training load.

Furthermore, in TP (in contrast to IPC), swimmers develop their endurance, speed, strength and flexibility abilities through a long phase of base training which precedes TP. It is assumed that the fitness level which was reached in the base training period mainly determines further performance and the peak form [37]. Hellard et al. [65] emphasized that training several weeks (i.e. 9-11) before a major competition clearly influences performance, with a positive impact of the general preparation mesocycle. Maglischo 
[7] claims that TP should begin when endurance and speed abilities are established on a proper, high level. So TP is a rest from hard training work which was done during the previous training phase [66, 67]. In case of 6-week and 8-week IPC, the concept is different. Swimmers are strained in various ways through high training loads, which should cause high adaptation effects (a cumulative training effect). This process involves a high risk of failure, because in top-level swimmers a high increase in efficiency and fitness levels (which could lead to a much better performance) is very rare at this stage. Superiority of taper over IPC strategies comes from (inter alia) absence of high training volume and intensity fluctuations. Undesirable effects of using IPC strategies include overtraining, which leads to a deficiency of the feasible recovery period in face of such high training loads and fatigue accumulation [68]. In TP, this risk is maximally reduced. Analysis of 6-week and 8-week IPC showed that those risky training load fluctuations occur three times during IPC: 1) very high increase in the training volume at the beginning of the accumulation phase 2) significant training intensity reduction combined with an increase in intensity at the beginning of the intensification phase 3 ) high training load reduction at the beginning of the transformation phase. Platonov [10] claims that in the case of 6-week IPC, failure of peak form preparation may come from a short duration of each IPC phase, which for many swimmers is not adequate and cannot provide enough supercompensation. Couts et al. [69] compared performance changes in well-trained triathletes after either 4 weeks of overload training and 2 weeks' taper or 4 weeks of casual training and the same 2 weeks' taper. There were the same performance gains in both groups after taper. These findings suggested that a length of the taper for the overload group may not have been sufficient to allow full recovery.

In comparison to IPC, taper strategy enables greater individualization of the training process. Many authors-practitioners [6, 7, 9, 37, 44, 66, 67] recommend proper execution of taper strategy. This involves (inter alia) training volume, intensity and frequency. It is said that training volume should not be reduced over 41 to $60 \%$ of the pre-taper values. Intensity of training should be maintained at the pre-taper level, which - as those studies show - is very effective. Furthermore, training frequency reduction reaching $20 \%$ or less will not affect the stroke technique $[6,7,37,44]$ It should be emphasized that in contrast to the IPC strategies, in TP training load reduction is gradual, which ensures almost risk-free adaptation to changing training conditions combined with current performance improvement.

Patterns of taper duration, which are not very rigorous, allow coaches to adjust the duration of TP to specific swimmer's abilities somewhere within limits of effective range between 4 and 28 days [44]. It is particularly important in the case of training swimmers representing different distance specializations. Olbrecht [4] estimated proper time proportions between specific pre-taper training and TP itself. Distance swimmers should go through three to six weeks of specific training, including race pace sets. Afterwards, they start 4-14 days of TP. Training sprinters, coaches utilize intense specific training, which lasts one to five weeks and then 2-4-week TP. It is worth noting that both distance and sprint swimmers devote a substantial part of their training to race-specific endurance training, swimming with En-3, Sp-1 intensities [7].

In $\mathrm{TP}$, different distance specializations utilize various training load reduction forms. Distance swimmers especially reduce the intensity of training, while sprinters mainly reduce the volume. Distance swimmers maintain a high level of training volume, and TP is generally short, because a longer period of decreased aerobic training could cause a drop in aerobic capacity [70,4]. Sprinters significantly reduce their training volume, and TP is quite long (even up to 4-6 weeks) [71], which helps to enhance anaerobic power $[3,7,12,24,25,43,59,72,73]$. According to Trappe et al. [12], the main mechanisms 
responsible for enhancing muscular power are changes in single muscle fibres and their contractile properties. After taper their observed 30\% increase in peak isometric force of Type IIa muscle fibres and 2.5 times larger absolute power of these fibres. Type I muscle fibres were almost unaffected by taper. It is also worth mentioning that taper has also been observed to increase distance per stroke [74].

A well-designed training period preceding the main competition is aimed at reaching the peak form, which allows swimmers to improve their performance level [37], as well as at maintaining a high fitness level during the competition period for as long as possible.

Available literature does not offer critical reports on performance gains due to IPC strategy execution in the swimmers' training program. Platonov [10] reports that at 1976 Montreal Olympic Games, swimmers from East Germany, after having 6-week IPC, made an enormous performance improvement due to high fitness level. As much as $40.3 \%$ of them beat their personal records. In addition, another $47.4 \%$ were nearly to achieve their personal best results. Platonov reported that only minor percentage of all swimmers reached their peak form at the end of competition or after them. He assumed that it could be connected with too short a transformation phase for some of the swimmers, but he has not considered another possible reasons. 8-week IPC realization resulted in even greater performance improvement among the German Democratic Republic (GDR) swimmers. He indicated that during the World Championship in Madrid in 1986 69.7\% of the swimmers beat their personal records. Olympic Games in Seoul in 1988 were equally successful, because $65.6 \%$ of GDR swimmers beat their personal bests [10].

A different approach was presented by Siewierski [28], who analysed the structure of IPC executed by Polish swimmers competing at the European Championship in Budapest in 2006. Siewierski presented data on swimmers' performance gains after 9-week IPC. It is to be noted, however, that while five out of eight swimmers made performance improvements, they were rather average, between $0.2-1.7 \%$.

The authors mentioned above could be accused of not mentioning the risk of failure due to high fatigue accumulation caused by varied training stimuli and sudden training volume and intensity changes [2]. In this regard, research by Costill et al. [74] is particularly interesting. They examined an influence of the training volume on college swimmers' performance. The research was aimed at identifying effects of redoubling the training volume for six weeks. Simultaneously, the second swimmers' group (with a similar performance level) maintained pre-experimental training loads. In the group which increased the training volume, performance at distances 50-100 yards decreased by 1.0-1.5\%. But at distances of 200 yards and 3000 meters their performance was better up to 1.4-2.9\%. Swimmers from the control group maintained the same performance level in races at 50 and 100 yards, but there was a significant increase in their times (1.5-2.5\%) at 200 yards and 3000 meters races. The authors concluded that a temporary increase in the training volume does not affect the fitness level in a crucial way. The same effects could be achieved by executing a lower training volume. Furthermore, an increase in the training volume might be damaging for the fitness level, especially affecting power and speed abilities, and therefore sprint performance [24, 75].

In summary, the presented information allows for a conclusion that the TP strategy gives more chance of gaining performance improvement with a lower risk of failure. Mujika and Padilla [9] emphasized that "tapering strategies are usually effective at improving performance, but they do not work miracles!" They confirmed this assumption with hard data. Average improvement connected with different forms of TP was $3 \%$, usually ranging between $0.5 \%$ and $6 \%$. It is important to emphasize that gentle training load reduction 
during TP allows for affecting the current efficiency and fitness level without losing control over them. Research by Mujika et al. [76], who have investigated international-calibre swimmers' performance, showed that less than $40 \%$ of them swim at their season's best level at major competitions. Study of Mujika et al. [8] aimed at determining the effects of the final three weeks of training before the Sydney Olympic Games in 2000 showed that the average performance improvement amounted to $2.18 \pm 1.50 \%$. Furthermore, the authors presented data on differences in time results, which amounted to $1.62 \pm 0.80 \%$ between the first and the fourth place. They also specified the expected performance improvements while using various TP strategies. Mujika and Padilla [9] claimed that exponential TP strategy could bring performance improvement of about 3\%; however, they pointed out that the fast-decay form of exponential TP is the most effective form of TP.

\section{CONCLUSIONS}

Comparative analysis of literature discussing and comparing TP and IPC enables the following conclusions to be drawn.

The possibility of gaining a substantial supercompensation effect due to high training loads is the main reason for using IPC strategies [10, 28]. It is marked by intentional implementation of high training volume followed by its decrease with a simultaneous increase in training intensity, which could be seen as a reflection of the whole season's training plan [19]. In IPC, regeneration of swimmer's body after overreaching is supposed to be reached by a sudden, step decrease in the training load. The expected effect of this procedure is to gain significant performance improvement, even up to a few percent [10]. IPC is commonly implemented in 6- and 8-week forms, but 8-week IPC seems to be more effective when it comes to reaching high performance enhancement [10]. Theoretically, IPC strategy allows only for manipulating the training content, while the duration of that stage and particular phases of its structure remain unchanged. The fact that swimmers representing different distance specializations have to execute training with the same time structure is the main drawback of this strategy, and reaching the peak form before or after the main competition due to overtraining after high training loads is its most common failure. One of the main presumptions of TP indicates fatigue as a reason for a temporary low performance level. In TP, at an appropriate moment, training volume and frequency reduction is implemented together with maintaining the intensity level. From all TP forms, the exponential ones seem to have the most positive impact on performance: exponential taper-fast decay and exponential taper-slow decay. Performance gains could be up to $4 \%-5 \%$ [9]. It is hard to show unambiguously which one is a more effective way of reaching a high performance level $[9,44,51]$. 2-week TP with a maximum frequency decrease of $20 \%$ of pre-taper values is the most optimal [6].

TP and IPC are two different strategies for peak form preparation. In both of them, it is assumed that the physiological mechanism of supercompensation results in performance gains. Due to a lower risk of overtraining (which in IPC results in recovery period elongation) and high implemented training load individualization, TP ensures the greatest possibility of reaching the peak form at a desirable moment among all methods. It could be due to the relative novelty of the TP method.

\section{PRACTICAL APPLICATIONS}

Coaches of fully developed, senior swimmers are recommended to choose the exponential tapering methods of peak form preparation. Swimmers' distance specialization, sex, age, level of regeneration abilities should be taken into consideration during the taper phase planning. 


\section{REFERENCES}

[1] Bompa TO, Haff GG. Periodization: Theory and methodology of training. 5th ed. Champaign, IL: Human Kinetics; 2009.

[2] Raglin JS, Koceja DM, Stager JM, Harms CA. Mood, neuromuscular function, and performance during training in female swimmers. Med Sci Sports Exerc. 1996;28(3):372-377. https://doi.org/10.1249/00005768-199603000-00013

[3] Papoti M, Martins LE, Cunha SA, Zagatto AM, Gobatto CA. Effects of taper on swimming force and swimmer performance after an experimental ten-week training program. J Strength Con Res. 2007;21(2):538-542. https://doi. org/10.1519/00124278-200705000-00043

[4] Olbrecht J. The Science of Winning. Planning, Periodizing and Optimizing Swim Training: F\&G Partners; 2000.

[5] Skorski S, Mujika I, Bosquet L, Meeusen R, Coutts AJ, Meyer T. The Temporal Relationship Between Exercise, Recovery Processes, and Changes in Performance. Int J Sport Physiol. 2019;14(8):1015-1021. https://doi.org/10.1123/ ijspp.2018-0668

[6] Bosquet L, Montpetit J, Arvisais D, Mujika I. Effects of tapering performance: a meta-analysis. Med Sci Sports Exerc. 2007;39(8):1358-1365. https://doi.org/10.1249/mss.0b013e31806010e0

[7] Maglischo EW. Swimming fastest. Champaign, IL; Human Kinetics; 2003.

[8] Mujika I, Padilla S, Pyne D. Swimming performance changes during the final 3 weeks of training leading to the Sydney 2000 Olympic Games. Int J Sports Med. 2002; 23(08):582-587.

[9] Mujika I, Padilla S. Scientific bases for precompetition tapering strategies. Med Sci Sports Exerc. 2003;35(7):11821187. https://doi.org/10.1249/01.MSS.0000074448.73931.11

[10] Platonow VN. Trening wyczynowy w pływaniu. Struktura i programy [High-performance swimming training. Structure and programs]. Warszawa: Centralny Ośrodek Sportu; 1997. Polish.

[11] Platonov VN. Periodization of sports training. General theory and its practical application.2013.

[12] Trappe S, Costill D, Thomas R. Effect of swim taper on whole muscle and single muscle fiber contractile properties. Med Sci Sports Exerc. 2001;33(1):48-56. https://doi.org/10.1097/00005768-200101000-00009

[13] Issurin V. Block periodization versus traditional training theory: a review. J Sports Med Phys Fitness. 2008; $48(1): 65$.

[14] Lewin G. Swimming sport. A textbook for trainers, tutor and sports teacher. Berlin: Sportverlag; 1970.

[15] Perkowski K. Basic terms in training terminology In: Bartkowiak E. Swimming. Pływanie. Program szkolenia dzieci i młodzieży [Training program for children and youth]. Warszawa: Centralny Ośrodek Sportu; 1997. Polish.

[16] Kuipers H. Training and overtraining. Med Sci Sports Exerc. 1998;30:1137-1139. https://doi.org/10.1097/00005768$199807000-00018$

[17] Aubry A, Hausswirth C, Julien L, Coutts AJ, Le Meur Y. Functional overreaching: the key to peak performance during the taper? Med Sci Sports Exerc. 2014;46(9):1769-1777. https://doi.org/10.1249/MSS.0000000000000301

[18] Gibala MJ, MacDougall JD, Sale DG. The effects of tapering on strength performance in trained athletes. Int J Sports Med. 1994;15(08):492-497. https://doi.org/10.1055/s-2007-1021093

[19] González-Boto R, Salguero A, Tuero C, González-Gallego J, Márquez S. Monitoring the effects of training load changes on stress and recovery in swimmers. J Physiol Biochem. 2008;64(1):19-26. https://doi.org/10.1007/BF03168231

[20] Neary JP, Martin TP, Reid DC, Burnham R, Quinney HA. The effects of a reduced exercise duration taper programme on performance and muscle enzymes of endurance cyclists. Eur J Appl Physiol. 1992;65(1):30-36. https://doi.org/10.1007/ BF01466271

[21] Thomas L, Mujika I, Busso T. Computer simulations assessing the potential performance benefit of a final increase in training during pre-event taper. J Strength Con Res. 2009;23(6):1729-1736. https://doi.org/10.1519/ JSC.0b013e3181b3dfa1

[22] Avalos M, Hellard P, Chatard JC. Modeling the training-performance relationship using a mixed model in elite swimmers. Med Sci Sports Exerc. 2003;35(5):838. https://doi.org/10.1249/01.MSS.0000065004.05033.42

[23] Thomas L, Busso T. A theoretical study of taper characteristics to optimize performance. Med Sci Sports Exerc. 2005;37(9):1615-1621. https://doi.org/10.1249/01.mss.0000177461.94156.4b

[24] Costill DL, King DS, Thomas R, Hargreaves M. Effects of reduced training on muscular power in swimmers. Phys Sportsmed.1985;13(2):94-101. https://doi.org/10.1080/00913847.1985.11708748

[25] Johns RA, Houmard JA, Kobe RW, Hortobágyi T, Bruno NJ, Wells JM, Shinebarger MH. Effects of taper on swim power, stroke distance, and performance. Med Sci Sports Exerc. 1992;24(10):1141-1146. https://doi.org/10.1249/00005768199210000-00012

[26] Urhausen A, Kindermann W. Diagnosis of overtraining: what tools do we have? Sports Med. 2002;32(2):95-102.

[27] Busso T. Variable dose-response relationship between exercise training and performance. Med Sci Sports Exerc. 2003;35(7):1188-1195. https://doi.org/10.1249/01.MSS.0000074465.13621.37

[28] Siewierski M. Volume and structure of training loads of top swimmers in direct starting preparation phase for main competition. Pol J Sport Tourism. 2010;17(4)

[29] Issurin V. Principles and Basics of Advanced Athletic Training. Michingan; USA, Ultimate Athlete Concept; 2008.

[30] Matveyev LP. Fundamentals of sports training. Moscow; Physical Culture and Sport; 1977.

[31] Platonov VN. The basis of Modern training process periodization in high-performance athletes for year preparation. Research Yearbook. National University of Ukraine on Physical Education and Sport. 2006;12(2):176-180.

[32] Platonov VN. Adaptacja w sporcie [Adaptation in sport]. Warszawa: Resortowe Centrum metodyczno-Szkoleniowe Kultury Fizycznej i Sportu; 1990. Polish.

[33] Costill DL, Flynn MG, Kirwan JP, et al. Effects of repeated days of intensified training on muscle glycogen and swimming performance. Med Sci Sports Exerc. 1988;20(3):249-254. https://doi.org/10.1249/00005768-198806000-00006

[34] Kirwan JP, Costill DL, Flynn MG, et al. Physiological responses to successive days of intense training in competitive swimmers. Med Sci Sports Exerc. 1988;20(3):255-259. https://doi.org/10.1249/00005768-198806000-00007 
[35] Pyne DB, Mujika I, Reilly T. Peaking for optimal performance: Research limitations and future directions. J Sports Sci. 2009;27(3):195-202. https://doi.org/10.1080/02640410802509136

[36] Colwin CM. Breakthrough Swimming. Stroke Mechanics, Training Methods, Racing Techniques. Champaign, IL: Human Kinetics; 2002.

[37] Mujika I, Padilla S, Pyne D, Busso T. Physiological changes associated with the pre-event taper in athletes. Sports Med. 2004;34(13):891-927. https://doi.org/10.2165/00007256-200434130-00003

[38] Bishop D, Edge J. The effects of a 10-day taper on repeated-sprint performance in females. J Sci Med Sport. 2005;8(2):200-209. https://doi.org/10.1016/S1440-2440(05)80011-8

[39] Houmard JA, Costill DL, Mitchell JB, Park SH, Hickner RC, Roemmich JN. Reduced training maintains performance in distance runners. Int J Sports Med. 1990;11(01):46-52. https://doi.org/10.1055/s-2007-1024761

[40] Houmard JA. Impact of reduced training on performance in endurance athletes. Sports Med. 1991;12(5):380-393 https://doi.org/10.2165/00007256-199112060-00004

[41] Neufer PD. The effect of detraining and reduced training on the physiological adaptations to aerobic exercise training. Sports Med. 1989;8:302-320. https://doi.org/10.2165/00007256-198908050-00004

[42] Shepley B, MacDougall JD, Cipriano N, Sutton JR, Tarnopolsky MA, Coates G. Physiological effects of tapering in highly trained athletes. J Appl Psychol. 1992;72(2):706-711. https://doi.org/10.1152/jappl.1992.72.2.706

[43] Trinity JD, Pahnke MD, Sterkel JA, Coyle EF. Maximal power and performance during a swim taper. Int J Sports Med. 2008;29(06):500-506. https://doi.org/10.1055/s-2007-965784

[44] Mujika I, Padilla S. Detraining and loss of training induced physiological and performance adaptations: part I: short term insufficient stimulus. Sports Med. 2000;30(2):79-87. https://doi.org/10.2165/00007256-200030020-00002

[45] Banister EW, Carter JB, Zarkadas PC. Training theory and taper: validation in triathlon athletes. Eur J Appl Physiol. 1999;79:182-191. https://doi.org/10.1007/s004210050493

[46] Strzala M, Ostrowski A, Szygula Z. Altitude training and its influence on physical endurance in swimmers. J Hum Kinet. 2011;28:91-105. https://doi.org/10.2478/v10078-011-0026-9

[47] Klusewicz A, Malczewska J. Zmiany morfologii krwi i zdolności wysiłkowej pływaków pod wpływem treningu na średniej wysokości [Blood count and swimmers exercise capacity changes altered by medium-height training]. Sport Wyczynowy. 1999;(7-8):68-75. Polish.

[48] Wolski LA, McKenzie DC, Wenger HA. Altitude training for improvements in sea level performance. Is there scientific evidence of benefit? Sports Med. 1996;22(4):251-263. https://doi.org/10.2165/00007256-199622040-00004

[49] Berglund B. High altitude training: aspects of haematological adaptation. Sports Med. 1992;14(2):289-303. https:// doi.org/10.2165/00007256-199214050-00002

[50] Boutellier U, Deriaz O, Di Prampero PE, Cerretelli P. Aerobic performance at altitude: Effects of acclimatization and hematocrit with reference to training. Int J Sports Med. 1990;11(S 1):21-26. https://doi.org/10.1055/s-2007-1024849

[51] Hellard P, Avalos M, Hausswirth C, Pyne D, Toussaint JF, Mujika I. Identifying optimal overload and taper in elite swimmers over time. J Sports Sci Med. 2013;12(4):668-678.

[52] Chatard JC, Mujika I. Training load and performance in swimming. In: Biomechanics and medicine in swimming VIII, Jyväskylä, Finland; 1999, 429-434.

[53] Le Meur Y, Pichon A, Schaal K, et al. Evidence of parasympathetic hyperactivity in functionally overreached athletes. Med Sci Sports Exerc. 2013;45(11):2061-2071. https://doi.org/10.1097/00005768-199807000-00018

[54] Thomas L, Mujika I, Busso T. A model study of optimal training reduction during pre-event taper in elite swimmers. J Sports Sci. 2008;26(6):643-652. https://doi.org/10.1080/02640410701716782

[55] Houmard JA, Scott BK, Justice CL, Chenier TC. The effects of taper on performance in distance runners. Med Sci Sports Exerc. 1994;26(5):624-631. https://doi.org/10.1249/00005768-199405000-00016

[56] Izquierdo M, Ibañez J, Gonzalez-Badillo JJ, Ratamess NA, Kraemer WJ, Häkkinen K. et al. Detraining and tapering effects on hormonal responses and strength performance. J Strength Con Res. 2007;21(3):768-775. https://doi. org/10.1519/R-21136.1

[57] Murach K, Bagley J. Less is more: the physiological basis for tapering in endurance, strength, and power athletes. Sports. 2015;3(3):209-218. https://doi.org/10.3390/sports3030209

[58] Trinity JD, Pahnke MD, Reese EC, Coyle EF. Maximal mechanical power during a taper in elite swimmers. Med Sci Sports Exerc. 2006;38(9):1643-1649. https://doi.org/10.1249/01.mss.0000229104.39145.6b

[59] Houmard JA, Johns RA. Effects of taper on swim performance. Sports Med. 1994;17(4):224-232. https://doi. org/10.2165/00007256-199417040-00003 4

[60] Zaporozanow W, Sozanski H. Bezpośrednie przygotowanie do głównych startów [Immediate preparation for main competition]. In: Platonov VN, Sozanski H (ed.) Optimization of sports training structure. Warszawa: Resortowe Centrum Metodyczno-Szkoleniowe Kultury Fizycznej i Sportu; 1991; 240-252. Polish.

[61] Flynn MG, Pizza FX, Boone JB, Andres FF, Michaud TA, Rodriguez-Zayas JR. Indices of training stress during competitive running and swimming seasons. Int J Sports Med. 1994;15(01):21-26. https://doi.org/10.1055/s-2007-1021014

[62] Halson SL, Jeukendrup AE. Does overtraining exist? Sports Med. 2004;34(14):967-981. https://doi. org/10.2165/00007256-200434140-00003

[63] Zatsiorsky VM. Science and Practice of Strength Training. Champaign: Human Kinetics; 2006.

[64] Yamamoto Y, Mutoh Y, Miyashita M. Hematological and biochemical indices during the tapering period of competitive swimmers. In: BE Ungerechts, K Wilke \& K Reischle (ed.) Swimming Science V. Champaign, IL: Human Kinetics Books, 1988, 17, 244-249

[65] Hellard P, Scordia C, Avalos M, et al. Modelling of optimal training load patterns during the 11 weeks preceding major competition in elite swimmers. Appl Physiol Nutr Metab. 2017;42(10):1106-1117. https://doi.org/10.1139/ apnm-2017-0180

[66] Mujika I, Busso T, Lacoste L, Barale F, Geyssant A, Chatard JC. Modeled responses to training and taper in competitive swimmers. Med Sci Sports Exerc. 1996;28(2):251-258. https://doi.org/10.1097/00005768-199602000-00015 
[67] Mujika I. The influence of Training Characteristics and Tapering on the Adaptation in Highly Trained Individuals: A Review. Int J Sports Med. 1998;19(07):439-446. https://doi.org/10.1055/s-2007-971942

[68] Hooper SL, Mackinnon LT, Howard ALF, Gordon RD, Bachmann AW. Markers for monitoring overtraining and recovery. Med Sci Sports Exerc. 1995;27:106-112. https://doi.org/10.1249/00005768-199501000-00019

[69] Coutts AJ, Slattery KM, Wallace LK. Practical tests for monitoring performance, fatigue and recovery in triathletes. J Sci Med Sport. 2007;10(6):372-381. https://doi.org/10.1016/j.jsams.2007.02.007

[70] Neufer PD, Costill DL, Fielding RA, Flynn MG, Kirwan JP. Effect of reduced training on muscular strength and endurance in competitive swimmers. Med Sci Sports Exerc. 1987;19(5):486-490. https://doi.org/10.1249/00005768198710000-00011

[71] Hellard P, Avalos-Fernandes M, Lefort G, Pla R, Mujika I, Toussaint JF, Pyne DB. Elite Swimmers' Training Patterns in the 25 Weeks Prior to Their Season's Best Performances: Insights Into Periodization From a 20-Years Cohort. Front Physiol. 2019;10. https://doi.org/10.3389/fphys.2019.00363

[72] Van Handel PJ, Katz A, Troup JP, Daniels JT, Bradley PW. Oxygen consumption and blood lactic acid response to training and taper. In: BE Ungerechts, K Wilke \& K Reischle (ed.), Swimming Science V, Champaign: 1988; (17):269-275.

[73] Weiss LW, Wood LE, Fry AC, et al. Strength/power augmentation subsequent to short-term training abstinence. J Strength Con Res. 2004;18(4):765-770. https://doi.org/10.1519/00124278-200411000-00014

[74] Costill DL, Thomas R, Robergs RA, Pascoe D, Lambert C, Barr S, Fink WJ. Adaptations to swimming training: influence of training volume. Med Sci Sports Exerc. 1991;23(3):371-377. https://doi.org/10.1249/00005768-199103000-00017

[75] D’acquisto LJ, Bone M, Takahashi S, Langhans G, Barzdukas AP, Troup JP. Changes in aerobic power and swimming economy as a result of reduced training volume. Swim Sci. 1992;201-205.

[76] Mujika I, Villanueva L, Welvaert M, Pyne DB. Swimming Fast When It Counts: A 7-Year Analysis of Olympic and World Championships Performance. Int J Sport Physiol. 2019;14(8):1132-1139. https://doi.org/10.1123/ijspp.2018-0782 